\title{
Dependence of Wave-Breaking Statistics on Wind Stress and Wave Development
}

\author{
Kristina B. Katsaros and Serhad S. Ataktuirt
}

Deparment of Atmospheric Sciences, University of Washington, Seattle, Washington 98195.

\begin{abstract}
Summary
Incidence of wave breaking for pure wind driven waves has been studied on Lake Washington at wind speeds up to $8 \mathrm{~m} \mathrm{~s}^{\prime}$. Video recordings were employed to identify and categorize the breaking events in terms of micro-scale, spilling and plunging breakers. These events were correlated with the magnitude of the wave spectrum measured with a resistance wire wave gauge and band pass filtered berween 6 and $10 \mathrm{~Hz}$. An equivalent percentage of breaking crests were found for spilling and plunging events.

Wave forcing as measured by wind stress (or friction velocity, $u_{*}$, squared) and by inverse wave age. $u_{0} / C_{p}$ where $C_{p}$ is the phase velocity of the waves at the peak of the frequency spectrum, were found to be good predictors of percentage of breaking crests. When combined in a two parmeter regression, those two variables gave small standard deviation and had a high correlation coefficient (66\%). The combination of $u_{*}^{2}$ and $u_{0} / C_{p}$ can be understood in physical terms. Furthermore. for the larger values of $u^{2}$. the dependence of wave breaking on wave age was stronger than at the low end of the values for $u_{*}^{2}$ and $u_{*} / C_{p .}$. Thus, both the level of wave development as detemined by inverse wave age, which we may term relative wind effectiveness for wave forcing and the wind forcing on the water surface determine the incidence of wave breaking.
\end{abstract}

Substituting $U_{10}^{\mathbf{3 . 7 5}}$ (which is the dependence of whitecap cover found by Monahan and coworkers) an equivalent correlation was found to the prediction by $u_{\text {.. }}^{2}$. Slightly better standard deviation value and higher correlation coefficient were found by using a Reynolds number as predictor. A two-paramerer regression involving $u_{\text {, and }}^{2}$ Reynold's number proposed by Toba and his colleagues (e.g., Toba and Koga, 1986) which relates $u_{\text {? }}^{2}$ and peak wave frequency, improves the correlation even more but is less easy to interpret in physical terms.

The equivalent percentage of breaking crests obtained in our previous study (Weissman et al., 1984) was reported as $8.6 \%$ for a short record obrained at $U_{10 \mathrm{w}}$ of about $6 \mathrm{~ms}^{-1}$. Typical values in the current study for similar conditions are $6 \%$, which is consistent with the previous study in view of the scatter. In that study we did not have a video recording system, so the observed breaking may include more of the micro-scale breaking events, and the value, $8.6 \%$, is well within the range of highly probable

\section{INTRODUCTION}

Wave breaking can be a dramutic change in sea surface characteristics and occurs on many scales. It plays a sigmificant role in air-sea exchanges of momentum, energy and mass in various ways (c.g., Donelan, 1990; Banner, 1990). In particular, it is the dominant mechanism responsible for wave dissipation; it removes momentum and energy from the wave field and transfers the momentum to surfece currents and the energy into both turbulence and currents. The dissipation of wave energy, due 
to breaking, is one of the kev parameters in wave prediction models which are based on the energy iransfer equation:

$$
\frac{\partial E}{\partial t}+V \cdot \nabla E=S_{i n}+S_{n l}+S_{\text {dies }}
$$

where $E$ is the wave spectral energy density, $V$ is velocity at which the wave energy propagates (i.e., group velocity pius currents), $S_{\text {in }}$ is source function due to wind input, $S_{n l}$ is source function due to nonlinear wave-wave interactions, and $S_{\text {diss }}$ is source term due to dissipation. In the stare of the ar. third generation ocean wave prediction model, the WAM model (the WAMDI Group, 1988), $S_{\text {in }}$ based on field measurements has been adopted from thax of Snyder et al. (1981), $S_{n d}$ derived on theoretical grounds has been taken from Hasseimann et al. (1985) and, $S_{\text {diss }}$ inferred from the residual term in numerical energy balance experiments has the form proposed by Komen et al. (1984). Despire its imporance. $S_{\text {diss }}$ is the least known of these three source terms.

Whitecaps, which are related to the wave breating but also includes the more persistent visible foam parch, have been studied extensively by Monahan and coworizers using statistical analysis of photographs and video recordings (e.g., Monahan, 1968, 1971; Monahen and O'Muircheartaigh, 1980; Monahan et al., 1983; O'Muircheartaigh and Monahan. 1986; O'Muircheartaigh et al., 1991). In these studies areal whitecap coverage has been found to correlate with the $10 \mathrm{~m}$ neutral wind speed raised to the power 3.75, $U_{10 \mathrm{w}}^{3.75}$ (also see, Wu, 1979, 1986).

Because of the increased significance of small scale perturbations on the sea surface for the retum of incident radar signais and for microwave emisoions, renewed interest in defining wave breaking and relating its occurrence to other measurable quantities has developed (e.8., Banner and Fooks, 1985). Jesoup et al. (1990, 1991 a) and Bush et al. (1991) have related the sea spikes in radar retum at X. C and Ku bands to wave breaking observed from video records. The latter studies found that sea spikes often occurred without visible breaking events, but Jessup et al. (1991b) comment that the largest spikes in their study were all directly relatable to readily visible plunging breakers (i.e., dramatically breaking wave crests).

The Bragg scarter is the dominant mechanism responsible for the variations in the normalized radar becksearter cross section, $\sigma_{0}$, as a function of wind speed or stress. It is currenty recognized that breaking events may modify this relationship, especially since it is unlikely that occurrence of wave breaking has the same dependence on wind speed or stress as the part of the wave spectrum corresponding to Bragg scattering water waves. It has also been observed that wave breaking is reiated not only to the wind forcing but that details of the underlying sea state mus also be considered. Numerous studies have considered the hydrodynamic instability of the water surface itself, i.e., in situations with no atmospheric forcing at all (see other articles in this volume). On theoretical grounds 
Phillips (1988) predicted that contributions to $\sigma_{0}$ by breaking waves should be proportional to $u_{*}^{3}$. where $u_{0}$ is friction velocity defined through $\tau_{0} / Q=u_{0}^{2} \tau_{0}$ is wind stress at the sea surface and $Q$ is air density. Jessup et al. $(1990,1991 b)$ verified this relationship.

Thus, the variability of processes responsible for wave breaking events may also be responsible for some of the scatter found between measured radar cross sections and wind speed (or wind stress). So far as the relationship to wind stress is concemed, it is quite possible that the intensity of wave breaking affects the wind stress in a manner which more closely parallels the effect on radar backscanter than the relationship between $10 \mathrm{~m}$ neutral wind speed, $U_{10 N}$ and $\sigma_{0}$. It is customary to use $U_{10 \mathrm{~N}}$ rather than the true wind speed in this relationship. $U_{10 \mathrm{w}}$ is convertible to a wind stress by defining a relationship between the neutral drag coefficient, $C_{D N}$, and $U_{10 N}$ viz:

$$
\tau_{0}=e C_{D N} U_{\text {ION }}^{2}
$$

This relationship represents an average condition if typical values for $C_{D N}$ are used (e.g., Sinith. 1980; Liu et al., 1979). For anomalous wave breaking a different $C_{D N}$ value should probably be employed and $\sigma_{0}$ may be a very good measure of the effective $\tau_{0}$.

In this study we extend the work of Weisuman et al. (1984), who developed a technique for identifying breaking waves from the record of a resistance wire wave gauge. That srady was based on a limited time series and only visual observations of the conditions at the wave wire. In this study video recordings were employed.

A preliminary study on sea spikes and wave breaking by Bush et al. (1991) with data obtained on our Lake Washington site has been carried out. Further work on the retationship between wind and wave parameters, frequency of occurrence of wave breaking and radar cross-sections at $\mathrm{X}, \mathrm{C}$ and $\mathrm{Ku}$ bands will be reported eisewhere in the near future.

\section{EXPERIMENTAL SET-UP AND DATA SETS ANALYZED}

This work was carried out at our field station on Lake Washington where wind and waves arrive after an over water fetch of $7 \mathrm{~km}$ (Figure 1.a). A complete suite of environmental measurements was collected, which includes mean wind speed, temperaure and humidiry at $2 \mathrm{~m}$ and $8 \mathrm{~m}$ heights, turbulent fluxes of momentum, heas and water vapor at $8 \mathrm{~m}$ and wave height from a resistance wire wave gauge hanging from a boom extending $2 m$ upwind of the supporting platform (Figure 1.b). The wave wire was made of stainiess steel, $100 \mu \mathrm{m}$ in diameter.

For the purpose of this study, 10 data sets were analyzed. The length of each duta set is 2 hours. The experimental conditions during these data sets are summarized in Table I where for each run the 


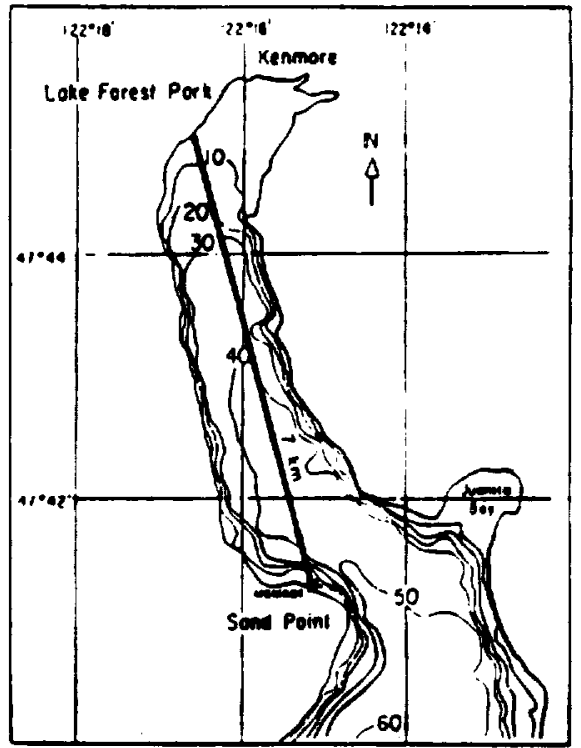

Figure 1a: The location of our field station (MSMAST) on Lake Washington. The tower is $15 \mathrm{~m}$ offshore and at a depth of $4 \mathrm{~m}$. The contours show the water depth in meters.

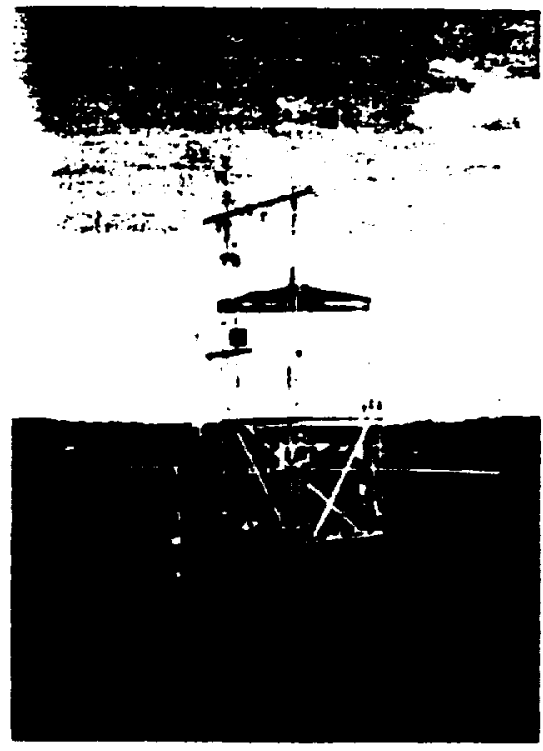

Figure Ib: The Lake Washington tower with meteorological instrumentation, wire wave gauge (at the left most tip of the low level boom) and the video camera (at the lower section of the platform).

mean values (the first line) and the standard deviations (the second line) of various environmental variables are provided.

\section{ANALYSIS}

Weissman et al. (1984) defined three types of breaking events; micro-scale, spilling and plunging. The three types are fairly easily separated. Typical examples are seen in Figure 2. Two independent observers of the video record agreed on the classification of the breaking events into these three categories with insignificant deviations. For the event to be counted in the video record it had to occur within a $0.1 \mathrm{~m}$ radius of the penetration of the wave wire through the mean water level.

For the wave breaking analysis, wave wire data were processed to obtain a time series of the spectral enersy density, $E_{6-10}$ in the frequency band 6-10 Hz with a sampling interval of $1 / 8$ second (see Ataltiltt, 1991). In our previous study (Weissman et al., 1984) we had devised a technique to detect the breaking events from such a time series by using the breaking criteria: (i) the spectral energy in a 
high frequency band exceeds a threshold, and (ii) the dara point is in the crest region (i.e., in the vicinity of a local maximum). Since the threshold, i.e., the absolute value of the measured band energy varies with wind speed (stress), gustiness, underlying long waves, currents etc., it had to be determined individually for each run. In the current study, this difficulty was greatly reduced by defining a new detection parameter, $N_{0}$, based on the fluctuating component of band energy normalized by its root-mean-square value;

$$
N_{0}=\frac{E_{6-10}-E_{6-10}}{E_{0,6-10}}
$$

Table I: General description of the dara sets analyzed. Duration of each run is two hours. For each run, the first row indicates the mean values and the second row the standard deviations.

\begin{tabular}{|c|c|c|c|c|c|c|c|c|c|c|c|}
\hline Run*: & \begin{tabular}{|c|} 
Date \\
YMMD
\end{tabular} & Time & $\begin{array}{l}U_{10 \mathrm{~N}} \\
(\mathrm{~m} / \mathrm{s})\end{array}$ & $u_{(m / s)}$ & $\begin{array}{r}T_{9-10} \\
\left({ }^{\circ} \mathrm{C}\right)\end{array}$ & $\begin{array}{l}T_{8} \\
\left({ }^{\circ} \mathrm{C}\right)\end{array}$ & $2 / L$ & $f_{f}(H z)$ & $\begin{array}{c}H_{s} \\
(m)\end{array}$ & $a k$ & $\frac{U_{\text {InN }}}{\mathrm{C}_{\mathrm{p}}}$ \\
\hline 1100 & $86 / 8 / 25$ & $15: 32$ & $\begin{array}{l}4.35 \\
0.38\end{array}$ & $\begin{array}{l}0.16 \\
0.02\end{array}$ & $\begin{array}{r}-1.15 \\
0.22\end{array}$ & $\begin{array}{l}23.26 \\
0.03\end{array}$ & $\begin{array}{r}-0.27 \\
0.04\end{array}$ & $\begin{array}{l}0.67 \\
0.04\end{array}$ & $\begin{array}{l}0.13 \\
0.02\end{array}$ & $\begin{array}{l}0.09 \\
0.01\end{array}$ & $\begin{array}{l}1.88 \\
0.23\end{array}$ \\
\hline 1101 & $86 / 8 / 25$ & $17: 36$ & $\begin{array}{l}4.69 \\
0.93\end{array}$ & $\begin{array}{l}0.17 \\
0.04\end{array}$ & $\begin{array}{r}-1.18 \\
0.31\end{array}$ & $\begin{array}{l}23.13 \\
0.11\end{array}$ & $\begin{array}{r}-0.24 \\
0.10\end{array}$ & $\begin{array}{l}0.70 \\
0.05\end{array}$ & $\begin{array}{l}0.12 \\
0.03\end{array}$ & $\begin{array}{l}0.09 \\
0.01\end{array}$ & $\begin{array}{l}2.09 \\
0.38\end{array}$ \\
\hline 1102 & $86 / 8 / 26$ & 11:20 & \begin{tabular}{|l|}
4.21 \\
0.34
\end{tabular} & $\begin{array}{l}0.15 \\
0.01\end{array}$ & $\begin{array}{c}-1.83 \\
0.24\end{array}$ & $\begin{array}{l}23.09 \\
0.12\end{array}$ & $\begin{array}{r}-0.21 \\
0.03\end{array}$ & $\begin{array}{l}0.75 \\
0.09\end{array}$ & $\begin{array}{l}0.09 \\
0.01\end{array}$ & $\begin{array}{l}0.08 \\
0.01\end{array}$ & $\begin{array}{l}2.01 \\
0.32\end{array}$ \\
\hline 1103 & $86 / 8 / 26$ & $15: 00$ & $\begin{array}{l}5.18 \\
0.32\end{array}$ & $\begin{array}{l}0.18 \\
0.01\end{array}$ & $\begin{array}{r}-2.70 \\
0.42\end{array}$ & $\begin{array}{l}23.78 \\
0.06\end{array}$ & $\begin{array}{r}-0.08 \\
0.03\end{array}$ & $\begin{array}{l}0.64 \\
0.03\end{array}$ & $\begin{array}{l}0.13 \\
0.00\end{array}$ & $\begin{array}{l}0.10 \\
0.00\end{array}$ & $\begin{array}{l}2.13 \\
0.20\end{array}$ \\
\hline 1104 & $86 / 8 / 27$ & 12:03 & $\begin{array}{l}3.36 \\
0.83\end{array}$ & $\begin{array}{l}0.12 \\
0.03\end{array}$ & $\begin{array}{r}-2.60 \\
0.62\end{array}$ & $\begin{array}{l}23.26 \\
0.06\end{array}$ & $\begin{array}{r}-0.25 \\
0.21\end{array}$ & $\begin{array}{l}0.70 \\
0.05\end{array}$ & $\begin{array}{l}0.10 \\
0.02\end{array}$ & $\begin{array}{l}0.07 \\
0.01\end{array}$ & $\begin{array}{l}1.51 \\
0.37\end{array}$ \\
\hline 1106 & $86 / 9 / 11$ & $18: 35$ & $\begin{array}{l}5.84 \\
1.01\end{array}$ & $\begin{array}{l}0.22 \\
0.04\end{array}$ & $\begin{array}{l}4.21 \\
0.33\end{array}$ & $\begin{array}{l}20.50 \\
0.05\end{array}$ & $\begin{array}{r}-0.44 \\
0.29\end{array}$ & $\begin{array}{l}0.55 \\
0.02\end{array}$ & $\begin{array}{l}0.18 \\
0.02\end{array}$ & $\begin{array}{l}0.12 \\
0.01\end{array}$ & $\begin{array}{l}2.05 \\
0.31\end{array}$ \\
\hline 1107 & $86 / 9 / 12$ & $14: 41$ & $\begin{array}{l}4.31 \\
0.42\end{array}$ & $\begin{array}{l}0.16 \\
0.02\end{array}$ & $\begin{array}{l}1.82 \\
0.32\end{array}$ & $\begin{array}{l}21.04 \\
0.05\end{array}$ & $\begin{array}{r}-0.56 \\
0.13\end{array}$ & $\begin{array}{l}0.66 \\
0.07\end{array}$ & $\begin{array}{l}0.13 \\
0.01\end{array}$ & $\begin{array}{l}0.10 \\
0.01\end{array}$ & $\begin{array}{l}1.81 \\
0.27\end{array}$ \\
\hline 1013 & $87 / 5 / 15$ & $12: 30$ & $\begin{array}{l}5.85 \\
0.92\end{array}$ & $\begin{array}{l}0.22 \\
0.04\end{array}$ & $\begin{array}{l}3.63 \\
0.11\end{array}$ & $\begin{array}{l}16.29 \\
0.01\end{array}$ & $\begin{array}{r}-0.34 \\
0.16\end{array}$ & $\begin{array}{l}0.55 \\
0.02\end{array}$ & $\begin{array}{l}0.19 \\
0.02\end{array}$ & $\begin{array}{l}0.12 \\
0.01\end{array}$ & $\begin{array}{l}2.05 \\
0.32\end{array}$ \\
\hline 1014 & $87 / 5 / 15$ & $14: 45$ & $\begin{array}{l}5.23 \\
1.12\end{array}$ & $\begin{array}{l}0.19 \\
0.05\end{array}$ & $\begin{array}{l}250 \\
0.26\end{array}$ & $\begin{array}{l}16.41 \\
0.05\end{array}$ & $\begin{array}{r}-0.44 \\
0.25\end{array}$ & $\begin{array}{l}0.59 \\
0.04\end{array}$ & $\begin{array}{l}0.17 \\
0.03\end{array}$ & $\begin{array}{l}0.11 \\
0.01\end{array}$ & $\begin{array}{l}1.96 \\
0.35\end{array}$ \\
\hline 89.10 & $89 / 7 / 19$ & 17:05 & $\begin{array}{l}6.83 \\
0.55 \\
\end{array}$ & $\begin{array}{l}0.26 \\
0.02\end{array}$ & $\begin{array}{l}1.09 \\
0.18\end{array}$ & $\begin{array}{l}22.06 \\
0.18\end{array}$ & $\begin{array}{r}-0.28 \\
0.05\end{array}$ & $\begin{array}{l}0.57 \\
0.06\end{array}$ & $\begin{array}{l}0.21 \\
0.03\end{array}$ & $\begin{array}{l}0.13 \\
0.01\end{array}$ & $\begin{array}{l}2.47 \\
0.16\end{array}$ \\
\hline
\end{tabular}




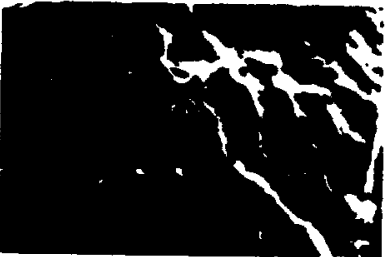

(a) micro-scale

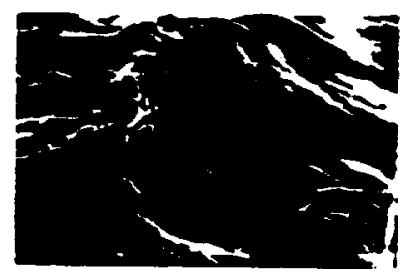

(b) spilling

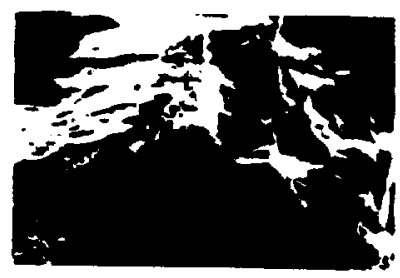

(c) plunging

Figure 2: The three types of wave breaking characterized from our video records.

where $\bar{E}_{6-10}$ and $E_{0,6-10}$ respectively, are the mean and standard deviation of $E_{6-10}$ calculared from a record typically 17 minutes in length. (Out of 66 reconds, two records were short -8.5 minute in duration. The statistics from these runs were included by simply doubling the number of breaking events.) Also, data points within $\pm 90^{\circ}$ phase of the local maximum were considered to be on the crest.

Long wave spectra were calculated from the $17 \mathrm{~min}$ wave height records. An equivalent number of wave crests. $N_{\text {crest }}$, in the record was defined as the duration, $T$, times the frequency of the waves at the peak of the spectrum, $f_{p}$ :

$$
N_{\text {crene }}=T f_{p}
$$

From video records. $N_{\text {break }}$ number of crests on which breaking occurred, was found. Percentage of crests with breaking.

$$
\% B=\frac{N_{\text {treak }}}{N_{\text {cres }}} \times 100
$$

was initially calculated separately for the event of plunging, spilling and micro-scate breakers. Since the frequencies of occurrence of spilling and plunging breakers were about the same and the micro-scale breaking tumed out to be ubiquitous and not well correlated with any turbulence or sea state measure. presentation of results has been done in terms of the sum of percentages of crests with breaking of type plungers and spillers, $\% B_{3}+m$

In a separnie study, Alakelitk (1991) bas malyzed the wind streas measurements of the currem study and edditional data runs, and obtained the relationship berween the drag coefficient and neutral $10 \mathrm{~m}$ mean wind speed valid for the fetch and water surface conditions at our Lake Washington site; 


$$
C_{\text {DN }}=\left(0.75+0.10 U_{10 N}\right) \times 10^{-3}
$$

This formula was used with the Liu et al. (1979) formulation for calculating turbulent fluxes from mean atmospheric measurements. The calculation of wind stress or equivalently the friction velocity from mean wind speed with this numerical scheme includes corrections for the influence of atmospheric stratification.

We also determined the inverse wave age, $U_{10 w} / C_{p}$ or $u_{o} / C_{p}$, for each nun, where $C_{p}=g / \omega_{p}$ is the phase speed of the dominant waves corresponding to the angular frequency, $\omega_{p}=2 \pi f_{p}$, of the speciral peaik and, $g$ is the acceleration due to gravity.

$\% B_{s+p}$ was correlated with various measures of the atmospheric turbulence and the relative wind forcing (identically equivalent to the inverse wave age). Both single and dual parameter linear regressions (Lapin, 1983) were calculated for several variables using the statistical program package Quartro-Pro. A curvilinear fit was also tried when it was noted that a linear fit for a certain variable was not optimal.

\section{RESULTS}

Figure 3a is a plot of $\% B$ determined from video records and separated into micro-scale, spilling and plunging types, versus $U_{10 \mathrm{w}}$. Micro-scale breaking occurs to about the same extent at all wind speeds, while spilling and plunging type breakers display a similar behaviour in frequency of occurrence which increases with increasing $U_{10 N}$. Therefore, further analyses were carried only for the combined effects of spilling and plunging breakers.

Comparisons of simultaneous video and wave wire reconds showed that, in general, micro-scale breaking is associated with events for which $N_{\sigma}<8$ and, spilling or plunging breaking may be characterized by $N_{\sigma} \geq 8$. Events with $N_{\sigma} \geq 12$ were always due to plungers. In Figure 3b, percentage of crests with spilling or plunging breaking, $q_{0} B_{s}+p$ determined from video records and percentage of crests with events $N_{\sigma} \geq 8$ obtained from wave wire records are plotted as a function of $U_{10 N}$. Although the distributions of the data points are similax, some differences in their magnitudes are visible: values from video records are smaller at low winds, and larger at high winds. These differences may result from, respectively, (i) sensitivity of wave wire to anall scale fearures which may not be visible on video records, (ii) insensitivity of wave wire to events that occur nearby but do not directly touch the sensor. The latter may be improved by using an array of wave wires which would allow spatial averaging.

In the atudies by Jessup ex al. (1990, 1991a) and Bush et al (1991) some spites in the radar backscater were found not to correspond to any visible breaking evens. Those events may be carried by the 

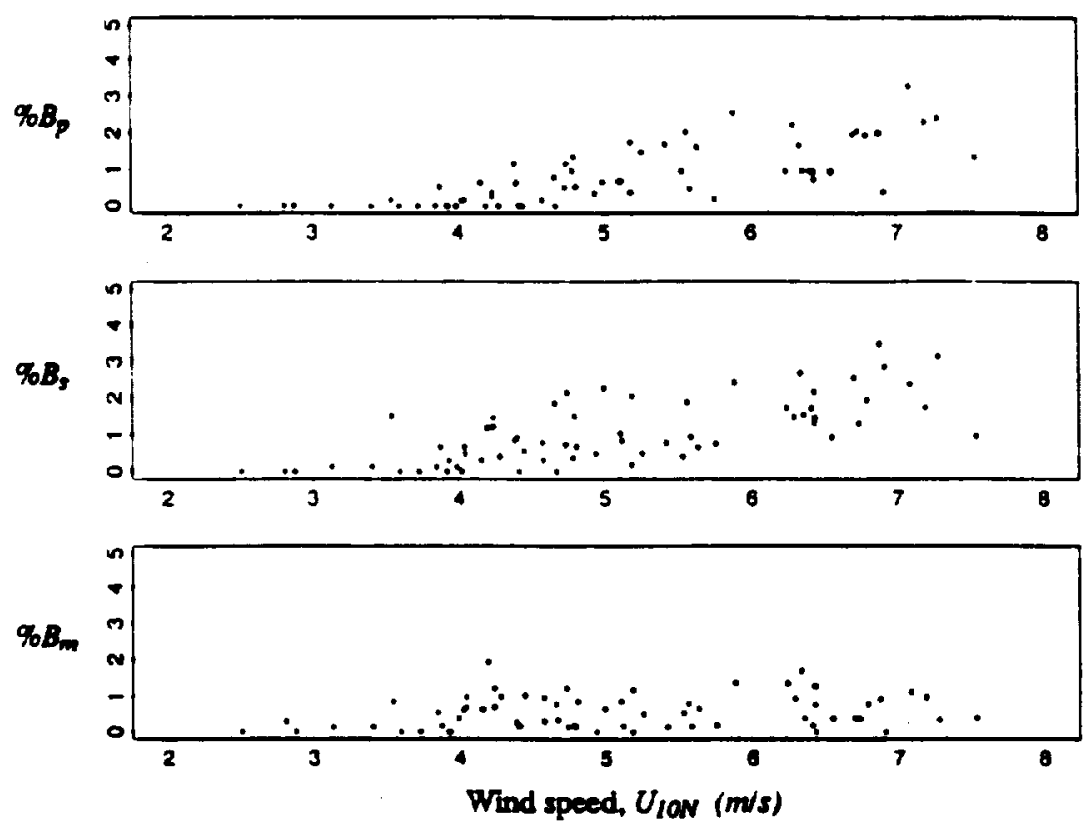

Figure 3a: Percentages of crests with micro-scale, $\varphi_{0} B_{m,}$ spilling, $\%_{s}$, or plunging, $\varphi_{0} B_{p}$. breaking versus wind speed, $U_{I O N}$, determined from video records.

same features (for instance shap comers) that cause $N_{\sigma}$ to be large (but still $N_{\sigma}<12$ ). This indicates that the radars are quite sensitive to such fearures, even if they do not cover the whole radar footprint.

Some of our $8<N_{0}<12$ events (or perhaps even a few of the $N_{0}>12$ cases) correspond to strong Doppler shifts causing the amplitudes of the signals a $6-10 \mathrm{~Hz}$, to be increased (being that they are really due to surface fearures of much lower intrinsic frequency. See, for instance, Ataktiurk and Katsaros (1987) for a discussion of Doppler shifis in wave wire data).

Figure 4 shows the dependence of $\% B_{s}+p$ on $R e, U_{10}^{3.73}, u_{0} / C_{p}$ and $u_{*}^{2}$ Reynoids number, Re, was defined as (Tobe and Koga, 1986):

$$
R_{e}=\frac{\mu_{0}^{2}}{v \omega_{p}}
$$




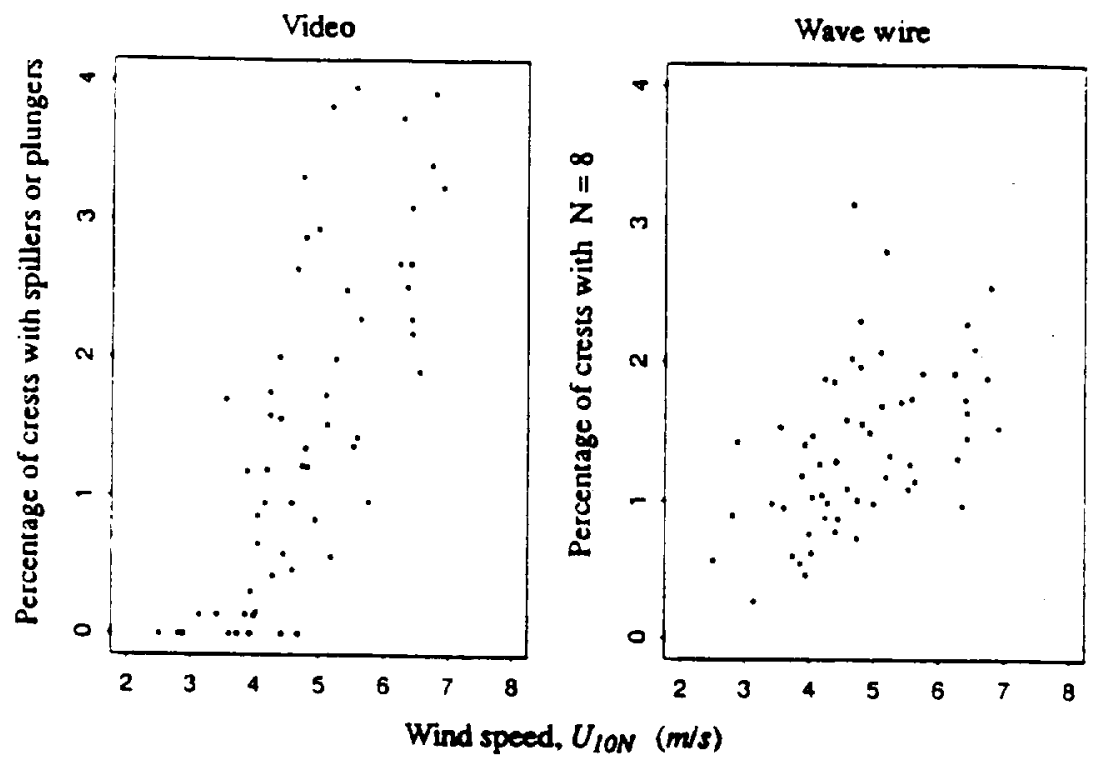

Figure 3b: Statistics of breaking events obtained from video and wave wire records versus wind speed, Uion.

where $v$ is the kinematic viscosity of air. All these parameters are about equally good predictors of $\% B_{s+F}$ However, from the statistics of the regression analysis provided in Table $\Pi$ it is seen that $u^{2}$ ? which explains $62 \%$ of the variations in $\% B_{s+\infty}$ is the best one among the individual variables used. (Although $u^{1.6}$ gives a slightly better correlation, for the limited data set the difference is nor significant.)

This point is further illustrated in Figure 5 of $\%_{s} B_{s}$ versus $u_{0} / C_{p}$ where the data points have been stratified according to the values of $u_{*}^{2}$. There is obviously a dependence on both the value of $u_{*}^{2}$, and $u_{*} / C_{p}$. Even though the rwo measures are not independent (since both contain $\left.u_{*}\right)$, it makes sense to examine for a certain wave age the variability in the $\varphi_{0},+p$ as a function of wind stress (here calculated from $U_{10 N}$ ). The regression lines show that for strong relative wind forcing (large inverse wave age), the increase in $\phi_{0} B_{s+p}$ as a function of $u_{*} / C_{p}$ is greater for large values of $u_{*}^{2}$ Also, from Table II it is seen that the pair, $u_{*}^{2}$ and $u_{*} / C_{p}$ explains a higher proportion of the variance of $\%_{s} B_{p}$ than $u_{*}^{2}$ alone with a proportional reduction of $11 \%$ in the previously unexplained variation.

Multiple regressions using $\left(u_{*}^{2}, R_{e}\right)$ or $\left(u_{*}^{2}, R_{e}, u_{*} / C_{p}\right)$ produced still betwer statistical results by explaining, respectively, $69 \%$ and $72 \%$ of the variance of $\% B_{s+}$. However, physical interpretations of 

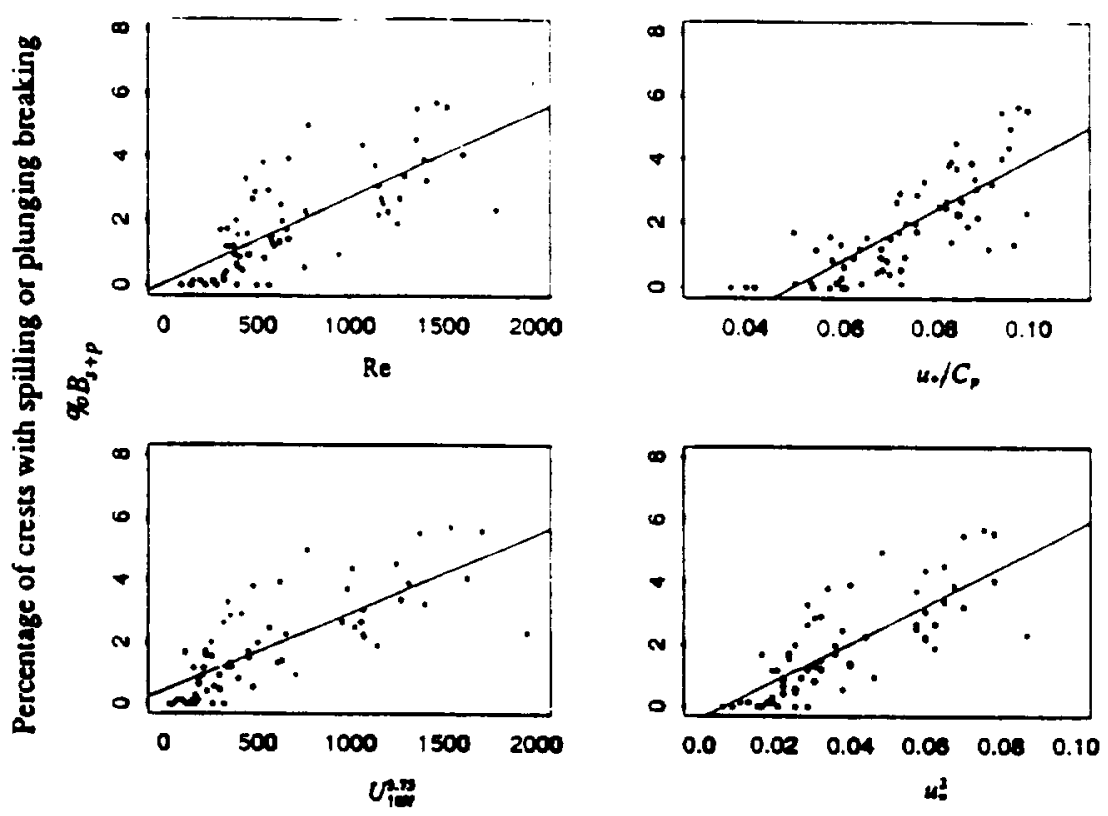

Figure 4: Linear regressions of $\% B_{s+p}$ for various predictors. A summary of the statistics obtained from regression analysis is provided in Table II.

Table II: Summary of the statistics obtained from regression andysis. The andyses were carried out following the definitions in Lapin (1983). Squaro-roct of the 3rd column is the correlation coefficient.

\begin{tabular}{|c|c|c|}
\hline Regression & $\begin{array}{l}\text { Standard Error } \\
\text { of Extimne }\end{array}$ & $\begin{array}{l}\text { Sample Coefficient } \\
\text { of Determination }\end{array}$ \\
\hline$\sigma_{0} B_{1+p}=0.03+2.68 \times 10^{-3} R e$ & 1.07 & 0.54 \\
\hline$\% B_{3+p}=0.44+2.52 \times 10^{-3} U_{10 N}^{3.73}$ & 1.02 & 0.58 \\
\hline $9 B_{s+p}=-3.97+79.48 u_{\cdot} / C_{p}$ & 0.99 & 0.60 \\
\hline$\% B_{s+p}=-0.41+61.09 u_{0}^{2}$ & 0.99 & 0.62 \\
\hline $9 B_{s+p}=-2.47+32.87 u_{0}^{2}+42.37 u_{0} / C_{p}$ & 0.93 & 0.66 \\
\hline
\end{tabular}

such combinations of variables are not as clear to us (but sea Toba and Koga (1986)). Also, in view of the large scawer, it does not make sense to try very complicated functional foms until a greuter data bese has been formed or a convincing physical relationship has been proposed. Therefore, these resulte are not included in Table II. 


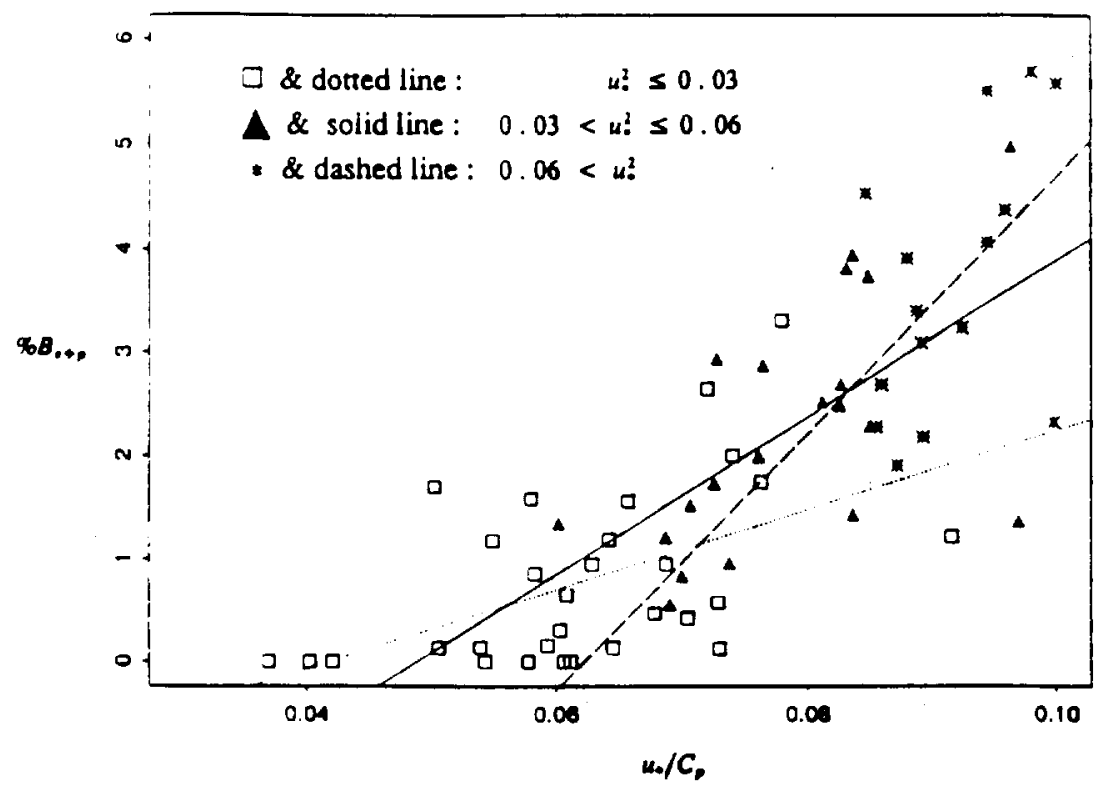

Figure 5: Percentage of crests with spilling or plunging breakers, $\% B_{s+p}$ versus $u_{\bullet} / C_{p}$. For three ranges of $u_{\text {? }}^{2}$ separate symbols and linear fits have been used, as indicated on the figure.

\section{DISCUSSIONS}

Predictability of the percentage of crests with spilling or plunging breakers, $\% B_{s}+p$ were investigated using a set of variables, $R e, U_{10}^{3.75}, u_{*} / C_{p}$ and $u_{*}^{2}$. These variables were chosen because such correlations make sense from a physical point of view. (For interpretations of the first two variables. see Toba and Koga (1986) and Wu (1979), respectively). In Tabie II we note that the highest sample coefficient of determination and the minimum standard error are obtained for the regression of $\% B_{s+p}$ as a function of $u_{*}^{2}$ and $u_{0} / C_{p}$. This result implies that for wave breaking both the magnitude of the wind stress and the degree of evolution of the surface waves are important.

It is eary to understand that young waves which are being strongly forced by a large wind stress should be breaking more frequently. Whether young waves, which are also short (i.e., the wavelength at the peak of the spectrum is short) breat more frequently then thase that have a wider spectral range through which to distribute the wind inpur by non-linear internctions - we intend to inves- 
tigate further. We hypochesize that the absolute width of the wave spectrum (or the value of the wave number at the peak of the spectrum) could be considered as another parameter for improving the prediction of the incidence of wave breaking.

Jessup et al. (1990) suggested that the information content of the frequency of spikes in the radar cross section may also be used to study the variability of wave breaking. We suggest that the band passed dara from an array of simple wave gauge wires may serve the same purpose. Since we have seen that $N_{0}>12$ consistently corresponds to visible breaking in all our wind wave records, this characteristic can now be used to count breaking waves. Enough cases can then be added by objective analysis to establish statistically significant information about the dissipation of surface waves under various forcing conditions as determined by wind stress and relative wind stress forcing. We are currently adding more cases on the breaking of pure wind waves on Lake Washington from two more summer seasons.

Once the interrelarionships have been establisbed for the simple case of wind driven waves, the role and imponance of swell (of variable amplitude and relative direction to the wind waves) as well as surface currents in wave breaking can then be studied more effectively.

Acknowledgements: We would like to thank Mr. Ralph C. Monis who spent countless hours watching the video records for detection and classification of breating events and assiated in data processing. This srudy was supported by the National Aeronaurics and Space Administration under Grant NAGW-1322.

\section{REFERENCES}

Ataktürk .S.S., 1991: Characterization of roughness elements on a water surface. Ph.D. Dissertation, Department of Atmospheric Sciences, University of Washington, Seattle, WA, 98195. 196 pp.

Ataltiirt, S.S. and K.B. Katsaros, 1987: Intrinsic frequency spectre of ahort gravity-capillary waves obtained from temporal measurements of wave heights on a lake. J. Geophys. Res., 92, 5131-5141.

Bemner, M.L., 1990: The influence of wave brentring on the enriace preasure distribution in wind-wave internctions. J. Fluid Mech., 211, 463-495.

Bemer, MLL and E.H. Fooks, 1985: On the miccownve reflectivity of amall-acale breaking weler waves. Proc. R. Soc. Lond., A 211, 93-109.

Bush, D.A., S.P. Gogineni, R.K. Moore, K.B. Kanaros, and S.S. Ataletit, 1991: A video-aided study of sea spikes in radar bacicscatter at moderate incidence. (Mmuscript submitted to IEEE Trans.) 
Hasselmann. S., K. Hasseiman. L.H. Allender, and T.P. Bametr, 1985: Computations and parameterizations of the noniinear energy transfer in a gravity-wave spectrum. Pant II: Parameterizations of the noninear transfer for applications in wave models. J. Phys. Oceanogr., 15, 1378-1391.

Jessup, A.T., W.C. Keller, and W.K. Melville, 1990: Messurements of sea spikes in microwave backscatter at moderate incidence. J. Geophys. Res., 95, 9679-9688.

Jessup, A.T., W.K. Melville, and W.C. Keller. 1991 a: Breaking waves producing sea spikes in microwave backscatter. Part II: Dependence on wind and wave conditions. (To appear in J. Geophys. Res.)

Jessup. A.T., W.K. Melville, and W.C. Keller, 1991b: Breaking waves producing sea spikes in microwave backscatter. Part I: Detection and visual verification. (To appear in J. Geophys. Res.)

Komen, GJ., S. Hasseimann, and K. Hasseimann, 1984: On the existence of a fully developed wind-sea spectrum. J. Phys. Oceanogr., 14, 1271-1285.

Lapin, L.L., 1983: Probabiliny and Statistics for Modern Engineering. PWS Publishers, B/C Engineering Division, Boston, MA, 624 pp.

Liu, W.T., K.B. Katsaros and J.A. Businger, 1979: Bulk parameterization of air-sea exchanges of hear and water vapor including the molecular constraints at the interface. J. Aomos. Sci., 36, 1722-1735.

Monahan, E.C., 1968: Sea spray as a function of low elevation wind speed. J. Geophys. Res.. $73,1127-1137$.

Monahan, E.C., 1971: Oceanic whitecaps. J. Phys. Oceanogr., 1, 139-144.

Monahan. E.C. and I.G. O'Muircheartaigh, 1980: Optimal power-law description of oceanic whitecap coverage dependence on wind speed. J. Phys. Oceanogr., 10, 2094-2099.

Monahan. E.C., D.E. Spiel and K.L. Davidson, 1983: Model of Marine Aerosol Generation via Whitecap and Wave Disruption. Ninth Conference Aerospace and Aeronautical Meseorol., Am. Meteorol. Soc.. Pp. 147-152.

O'Muircheartaigh, I.G. and E.C. Monahan, 1986: Statistical aspects of the relationship between oceanic whitecap coverage wind speed and other environmental factors. In Oceanic Whitecaps, E.C. Monahan and G.M. Niocaill, Eds., D. Reidelberg Publishing Company, pp. $125-128$.

O'Muircheartaigh, I.G., M. Claffey, and E.C. Monahan, 1991: Modeling the wind-dependence of whitecapping using hierarchical models and paranctric empirical Bayes methodology. Presenced in XX General Assembly of the IUGG, 11-24 August, 1991, Vienm, Austria. 
Phillips, O.M., 1988: Radar retums from the sea surface-Bragg scartering and breaking waves. J. Phys. Oceanogr., 18. 1065-1074.

Smith, S.D., 1980: Wind stress and heat lux over the ocean in gale-force winds. J. Phys. Oceanogr., 10, 709-726.

Snyder, R.L., F.W. Dobson. J.A. Ellion, and R.B. Long, 1981: Array measurements of atmospheric pressure fluctuations above surface gravity waves. J. Fluid Mech., 102, 1-59.

The WAMDI Group; S. Hasselmann, K. Hasselmann, E. Bauer, P.A.E.M. Janssen, G.J. Komen, L. Bentri, P. Lionello, A. Guillaume, V.C. Cardone, J.A. Greenwood, M. Reistadt, L. Zambresty, and J.A. Ewing, 1988: The WAM model-A third generation ocean wave prediction model. J. Phys. Oceanogr., 18, 1775-1810.

Toba, Y. and M. Koga, 1986: A parameter describing overall conditions of wave breating, whitecapping, ses-spray production and wind stress. In Oceanic Whitecaps, E.C. Monahan and G.M. Niocaill, Eds.. D. Reidelberg Publishing Company, pp. 37-47.

Weissman, M. A., K. B. Katsaros, and S.S. Ataltiirk, 1984: Detection of breaking events in a wind-generated wave field. J. Phys. Oceanogr., 14, 1608-1619.

Wu. J., 1979: Oceanic whitecaps and sea state. J. Phys. Oceanogr., 7, 1064-1068.

Wu, J., 1986: Whitecaps, bubbles, and spray. In Oceanic Whitecaps, E.C. Monahan and G.M. Niocaill, Eds., D. Reidelberg Publishing Company, pp. 113-124. 